\title{
Probit Model Analysis of Tourists' Revisit Intention to Nepal
}

\author{
Noora Shrestha \\ Department of Mathematics and Statistics, P.K. Campus, Tribhuvan University, Kathmandu, Nepal \\ Email: shresthanoora@gmail.com
}

How to cite this paper: Shrestha, N. (2021) Probit Model Analysis of Tourists' Revisit Intention to Nepal. Open Access Library Journal, 8: e7210.

https://doi.org/10.4236/oalib.1107210

Received: February 3, 2021

Accepted: February 16, 2021

Published: February 19, 2021

Copyright $\odot 2021$ by author(s) and Open Access Library Inc.

This work is licensed under the Creative Commons Attribution International License (CC BY 4.0).

http://creativecommons.org/licenses/by/4.0/

\section{(c) (i) Open Access}

\begin{abstract}
This study discusses on the identification of the tourists' destination satisfaction attributes and the influence of these factors on their revisit intention to Nepal. This study used the survey methodology for data collection and involved the distribution of self-administered questionnaires to a sample of tourists. An exploratory factor analysis, with principal component analysis and varimax rotation, was used to extract significant factors related to satisfaction with destination features. Using maximum likelihood method, a probit model was analyzed to test the impact of tourists' satisfaction with their revisit intention. The probit model predicts $93.5 \%$ of the cases correctly. The tourists were considered to be budget travellers as $92 \%$ of them spent less than $\$ 40$ per person per day during their visit. The result also shows that satisfaction with destination characteristics such as historic and religious places, experiencing different lifestyle, trekking \& mountaineering, adventure sports, and tourist guide service, are realized to significantly influence the probability of revisit intention of budget travellers to Nepal.
\end{abstract}

\section{Subject Areas}

Consumer Behavior, Tourism Economy, Applied Statistics

\section{Keywords}

Probit Model, Exploratory Factor Analysis, Varimax Rotation, Budget

Traveller, Revisit Intention, Nepal

\section{Introduction}

Tourism is considered as the major sector that contributes the national economy of a developing country by creating employment opportunities, generating revenue, and earning foreign currency (Terry, 2006 [1]; Kevin \& Irena, 2007 [2]). 
Nepal is taken as the naturally beautiful destination for mountaineers, people for white water rafting, researchers of the animal \& bird, rock climbers and adventurous people. The tourism in Nepal is largely focused on courageous trekking, mountaineering and it does attract a reasonable number of tourists including budget travellers (MoCTCA, 2019 [3]; MoCTCA, 2020 [4]).

Budget travellers or backpackers are independent young travellers who stay longer than usual length of travel, prefer a low budget for travel and accommodation, and desire to meet both other tourists and locals (Kevin \& Irena, 2007) [2]. Budget travellers are to be found in every village and city of a country throughout the world (Richards \& Wilson, 2004) [5]. They are more distinct than other tourists, having large range of interest, motivations, cultural diversity, age, class, and nationality. The foreign currency brought in by budget travellers often exceeds than the other mainstream tourists and they can approach and contribute to the marginalized social groups (Maoz, 2007) [6]. According to tourism statistics of Nepal, in January 2020, there was a record of 39.2\% international tourists arrival from Asian countries, followed by $26.3 \%$ from SAARC countries, $13.6 \%$ from Europe, 9.2\% from America and remaining from other countries (NTB, 2020) [7]. In Nepal, average expenditures per day of budget travellers were $\$ 20$ to $\$ 30$ while the average per day spending of other international tourist was $\$ 54$ in 2017 ; it was dropped to $\$ 44$ in 2018 . The average length of stay of overseas tourists in Nepal was 12 to 14 days depending on the season (MoCTCA, 2020) [4].

In January 2020, the tourist arrival was observed satisfactory resulting 79,686. These tourists were from the top six countries: India (21.7\%), China (15.9\%), USA (8.1\%), South Korea (6.3\%), Thailand (5.7\%), and Myanmar (4.7\%). The revenue generated from tourism in Nepal was $\$ 703,179$ thousand in 2018 (MoCTCA, 2020) [4]. It was perceived that the tourist influx is high during two points of the year February to April and September to November, making them the ultimate seasons for tourist arrival in Nepal. The purpose for travelling to Nepal was for holiday, trekking, and mountaineering followed by pilgrimage. The percentage of male tourists was higher than the female in last few years (MoCTCA, 2020) [4].

Revisit intention has been identified as an extension of satisfaction and a significant research topic in tourism studies (Lehto, O’Leary \& Morrison, 2004 [8]; Julaimi \& Salim, 2016 [9]). Some literatures reveal that satisfied tourists agree and have the tendency of revisit to the same destination to stay longer, contribute more intensively, and explore new locations (Bake \& Crompton, 2000 [10]; Khan, Chelliah \& Ahmed, 2017 [11]). The revisit intention is also considered as willingness to recommend the destination to others by spreading positive word of mouth (Sonmez \& Graefe, 1998 [12]; Pritchard \& Howard, 1997 [13]). There are numerous analyses verifying the positive impact of tourist satisfaction and perceived attractiveness on repeat tourism (Juaneda, 1996 [14]; Bigne, Sanchez \& Andreu, 2009 [15]; Um, Chon, \& Ro, 2006 [16]). The prominence of revisit in- 
tention of the traveller for the sustainability of the tourism business has been well proven by previous literature (Kozak, 2001 [17]; Loi, So, Lo \& Fong, 2017 [18]). According to Seetnah et al. 2020 [19], the satisfaction of the tourist with hotel accommodation quality, cost of living, development level, tourism attraction, and quality of information were important determinants of both tourist satisfaction and revisit intention. They conducted study with non-probability sampling method and data was analyzed using probit model.

In Nepal, the tourism promotional activities to attract tourists are largely focused on limited destination and on the features of tourism such as mountaineering, trekking, and jungle safari. There are some tourist destinations where regular plan, promotion, and attractive packages to the international tourists are rare. Repeat visitation is very imperative for the tourism industry of Nepal because these destinations are mainly relying on the loyal repeat visitors. The loyal visitors will increase their stay and share their experiences to other potential travellers to visit the destination (Pradhanang, 2000 [20]; Shrestha, 2000 [21]; Hampton, 2010 [22]).

Despite the phenomenal growth seen in January 2020, Nepal's tourism sector is far from reaching its peak potential. Although ministry of culture, tourism, and civil aviation produces tourism statistics every year, there is no precise data on repeat tourism and budget travellers such as demographic profile, trend and purpose of visit nevertheless Nepal being a popular budget traveller's destination. It is very important to understand that budget travellers immediately are fun lovers, independent travellers, and contributes to raise the income of local people. Budget travellers for trekking and adventure rend to consume local products, and stay in homestay or family owned teahouse, love local food; use locally owned transport, which in turn brings profit within the local community rather than the international hotel groups (Hampton, 2010 [22]; Scheyvens \& Russell, 2012 [23]). Hence, the present study intends to provide answers to the research questions; 1) What are the socio-demographic attributes of the budget traveller? 2) What are the significant factors influencing budget traveller's destination satisfaction characteristics on their revisit intention?

Budget travellers when compared to the mainstream tourists are more likely to travel low-income countries like Nepal, spend more time in travelling, contribute for cultural sustainability and be ready to endure hardships and inconveniences (Pearce, 2008) [24]. The budget travellers' tourism is most important and has a positive socio-economic impact for local communities they visit but Nepalese tourism stakeholders less acknowledge them. By reason of covid-19 pandemic, an international tourism may not resume anytime soon and hence it is necessary to rethink on the tourism strategy by focusing more on the significant factors without compromising the quality.

The aim of the present study is twofold; first, to identify the factors related to destination features contributing to satisfaction and second, to assess the influence of these factors on revisit intention of the budget traveller. 


\section{Materials and Method}

\subsection{Data Collection and Sampling Method}

A questionnaire survey method along with a cross-sectional research design was considered most suitable since it allowed measuring the revisit intention with destination satisfaction through the collection of data from budget travellers visiting Gandaki province of Nepal. In 2018, Gandaki province welcomed 400,000 international tourists generating income and significant employment. This province is well known for its natural beauty, organic resources, diverse geography, and social cultural heritages. Pokhara, the most popular tourist destination, is the capital city of this province. There are some districts of this province such as Lamjung, Manang, and Mustang, which are popular tourist destinations for sightseeing, pilgrimage site, and adventure trekking tours and sports. This province has identified tourism as one of the major sources for revenue generation (MoITFE, 2019) [25].

The items in the questionnaire, relating to destination satisfaction and revisit intention were identified from previous literature (Maoz, 2007 [6]; Lehto et al., 2004 [8]; Julaimi \& Salim, 2016 [9]). The socio-demographic characteristics, and the attributes people and heritage, natural environment and beauty, adventure, and tourist information were considered to be associated to destination satisfaction, and were treated as statistically significant explanatory variables in the model (Khan et al., 2017 [11]; Seetanah et al., 2020 [19]; Bam \& Kunwar, 2020 [26]). A five points Likert-type scale was espoused; least score " 1 " indicating strongly disagree and " 5 " is representing strongly agree for the factors in the questionnaire including destination satisfaction and outcome variable revisit intention measured on a dichotomous scale. Few open-ended questions were added that allow respondents to answer in open text format and share their knowledge, feelings and understanding.

A non-probability sampling method was preferred to select participants since the questionnaire was designed for English speaking tourists and the sampling frame for the tourist visiting the study area was not accessible. Although the lack of an obtainable sampling frame precludes the possibility of a probability sampling, there are still a number of choices existing in the non-probability samples. While non-probability samples do not convey the same weight as probability samples, they do still deliver the prospect to draw from a representative selection of the population (Kimberly, 2005 [27]; Lavrakas, 2008 [28]).

According to Nepal tourism statistics 2019, total international tourists travelled to Nepal were 1,197,191 from January to December 2019. Out of total arrival of tourists, 29\% were Asian-SAARC, 29\% were Asian others, 20\% were European, 9\% were Americans, 9\% were Oceania, and 4\% were others (MoCTCA, 2020) [4]. Proper attention was taken to acquire a 200 sample of tourists that will show the important socio-demographic characteristics of the population such as age, gender, purpose of a visit, budget, length of stay, and region. Sample was taken as a proportion of region wise distribution of arrivals. The inclusion crite- 
ria of the sample were 1) age more than 18 years, 2) visiting in Gandaki province for over a week, and 3) accommodated in homestay or budget lodges or family owned teahouses. Questionnaires were distributed during November to December 2019 to the respondent tourists who had been travelling in the same province during survey period.

\subsection{Method of Data Analysis}

Descriptive statistics were used as a preliminary analysis procedure to get an understanding of intrinsic substantial socio-demographic attributes of the budget traveller. To identify the factors related to destination descriptions contributing to budget travellers' satisfaction, exploratory factor analysis was used and binary probit model was analyzed to assess the influence of the extracted factors on revisit intention as a binary response variable. Binary probit model is suitable to provide detailed analysis of the intention to repeat tourism of the respondent (Shrestha, 2021 [29]; Uzunoz \& Akcay, 2012 [30]). All the statistical analysis was performed using STATA 14.

The factor extraction method is based on principal component analysis and the varimax orthogonal factor rotation method with Kaiser normalization. Kaiser-Meyer-Olkin test is used to measure the sampling adequacy. To check the multicollinearity among the variables, a determinant score is computed. Cronbach's alpha is calculated to examine the internal consistency or reliability of the data set (Cattel, 1973 [31]; Kaiser, 1958 [32]).

A probit model is a statistical probability model in which the variable of interest, Y, can take dichotomous values for example, revisit intention (RI), yes or no. There are some studies that display the application of probit model for the binary outcome variable (Uzunoz \& Akcay, 2012 [30]; Alabi et al., 2014 [33]). The purpose of the probit model is to estimate the probability that an observation with particular characteristics will fall into one of the two binary outcomes (Liao, 1994 [34]; Albert \& Chib, 1993 [35]).

In this study, the binary probit model was used to test the influence of budget travellers' satisfaction with various destination characteristics on their revisit intention, measured on a dichotomous scale. The probit analysis provides statistically significant findings of which destination satisfaction factors influence or not the probability of revisit of budget travellers. In binary probit model, revisit intention was taken as " 1 " for yes, while " 0 " for no.

For the probit model, the probability $\left(P_{i}\right)$ of selecting any alternative is given by

$$
P(Y=1 \mid X)=\Phi\left(\sum_{k=1}^{K} \beta_{k} X_{k}\right)=\int_{-\infty}^{\Sigma \beta_{k} X_{k}}(\sqrt{2 \pi}) \exp (\sqrt{2 \pi}) \exp \left(\frac{-t^{2}}{2}\right) \mathrm{d} t
$$

where $\Phi$ is the standard normal cumulative distribution function. The equation for the probability of non-event is given by

$$
P(Y=0 \mid X)=1-\Phi\left(\sum_{k=1}^{K} \beta_{k} X_{k}\right)
$$


The relationship between a particular variable and the predicted probability is interpreted by marginal effect. To interpret the probit model, partial derivatives of probability with respect to an independent variable, $X_{k}$ is examined. The marginal effect can be derived as

$$
\frac{\partial \operatorname{Prob}(y=1)}{\partial x_{k}}=\Phi\left(\sum_{k=1}^{K} \beta_{k} X_{k}\right) \beta_{k}
$$

where, $\Phi$ indicates the standard normal probability density function. The probit model can be written as

$$
Y=\beta_{0}+\beta_{1} X_{1}+\beta_{2} X_{2}+\cdots+\beta_{k} X_{k}+\varepsilon_{k}
$$

where, $Y=$ binary dependent variable, $X=$ explanatory variable, $\beta=$ parameter to be estimated, $\varepsilon=$ error term (Aldrich \& Nelson, 1984 [36]; Greene, 1993 [37]).

\section{Results and Discussion}

\subsection{Socio-Demographic Information}

On the basis of survey results, of the total 200 sample, the male participants (63\%) were more than the female (37\%) participants which is consistent with the Nepal tourism statistics; the percentage of male tourists was higher than the female in last few years (MoCTCA, 2020) [4].

Table 1 displays the minimum and maximum ages of the participants that were 18 and 56 years respectively. The mean age of participants in the age group from 18 to 56 years was 35.7 years and standard deviation $=10.27$. The majority $(80 \%)$ of the tourists were from the age group $16-45$ years. This finding is agreeing with the Nepal tourism statistics that shows most of tourists in 2019 were between the ages 16 to 60 years (MoCTCA, 2020) [4]. In addition, the respondents were from various parts of the world. The respondents were selected from different regions based on the Nepal tourism statistics 2019. The region wise distribution of tourists was Asian-SAARC (29.5\%), Asian-others (29\%), European (20\%), Americans (9\%), Oceania (8.5\%), and other (4\%).

There are various purposes of visiting Gandaki province. 32\% of the tourists visited with the purpose of holiday and pleasure. Similarly, 30.5\% of the tourist came for adventure including trekking and mountaineering, $11 \%$ for volunteering and academic, $16.5 \%$ for entertainment, video, and photography, and $10 \%$ for pilgrimage purpose. The average length of stay of respondents in this study was found to be 12.72 days with standard deviation 4.56 , which is consistent with the average length of stay 12.4 days in 2018 (MoCTCA, 2020) [4]. 4\% of tourists visited Gandaki province for a minimum five-day stays, and the maximum length of stay of $7.5 \%$ of tourists was 20 days.

In this study, the travel expenditure of tourists on their stay in Gandaki province was ranged from $\$ 20$ and more per person per day. The survey result illustrates that out of all respondents, $45.5 \%$ of tourists spent lower amount $\$ 20$ to $\$ 30,46.5 \%$ spent mid range expenditure $\$ 30$ to $\$ 40,4.5 \%$ spent high range $\$ 40$ to $\$ 50$, and $3.5 \%$ of them spent very high range $\$ 50$ or more. This expenditure of 
tourists was lower than the average expenditure of the tourist revealed by tourism statistics of Nepal (MoCTCA, 2020) [4]. According to tourism statistics of Nepal, the average spending per tourist per day was \$54 in 2017 and \$44 in 2018 for all types of tourists. The average expenditure per person per day of the tourist was found to be $\$ 40$ in a previous study conducted in the same destination (Bam \& Kunwar, 2020) [26]. Hence, the participants of this study were assumed to be budget traveller as $92 \%$ of them spent less than $\$ 40$ per person per day during their visit.

Table 1. Socio-demographic information.

\begin{tabular}{|c|c|c|c|}
\hline Variables & Categories & $\mathbf{N}$ & $\%$ \\
\hline \multirow{3}{*}{ Gender } & Male & 126 & 63 \\
\hline & & & \\
\hline & Female & 74 & 37 \\
\hline \multirow{3}{*}{ Age (years) } & $16-30$ & 62 & 31 \\
\hline & $31-45$ & 98 & 49 \\
\hline & $46-60$ & 40 & 20 \\
\hline \multirow{6}{*}{$\begin{array}{l}\text { Region wise } \\
\text { Distribution }\end{array}$} & Asian-SAARC & 59 & 29.5 \\
\hline & Asian-others & 58 & 29 \\
\hline & European & 40 & 20 \\
\hline & Americans & 18 & 9 \\
\hline & Oceania & 17 & 8.5 \\
\hline & Other & 8 & 4 \\
\hline \multirow{5}{*}{ Purpose of Visit } & Holiday & 64 & 32 \\
\hline & Adventure & 61 & 30.5 \\
\hline & Volunteering \& academic & 22 & 11 \\
\hline & Entertainment, video \& photography & 33 & 16.5 \\
\hline & Pilgrimage & 20 & 10 \\
\hline \multirow{3}{*}{ Length of Stay (days) } & $5-9$ & 60 & 30 \\
\hline & $10-14$ & 68 & 34 \\
\hline & $15-20$ & 72 & 36 \\
\hline \multirow{4}{*}{$\begin{array}{c}\text { Expenditure per person } \\
\text { per day }(\$)\end{array}$} & $\$ 20-\$ 30$ & 91 & 45.4 \\
\hline & $\$ 30-\$ 40$ & 93 & 46.5 \\
\hline & $\$ 40-\$ 50$ & 9 & 4.5 \\
\hline & $\$ 50$ and more & 7 & 3.5 \\
\hline
\end{tabular}




\subsection{Factor Analysis}

Table 2 displays results obtained from exploratory factor analysis using varimax rotation. It presents the value of Kaiser-Meyer-Olkin (KMO) test that is equal to $0.778>0.6$, and used in research to determine the sampling adequacy of data that are to be used for factor analysis. The Bartlett's test is highly significant ( $\mathrm{p}<$ 0.001 ), and demonstrates there is certain relationship between the variables. The value for the determinant of the correlation matrix of explanatory variables is a measure of the severity of multicollinearity. The existence of multicollinearity in the model increases the standard errors of each coefficient, and lead to increasing complexity in the outcome of the statistical analysis (Shrestha, 2020) [38]. The determinant score of the correlation matrix is $0.027>0.0001$ indicating absence of multicollinearity among the variables.

Table 2. Rotated component matrix of satisfaction with destination attributes.

\begin{tabular}{|c|c|c|c|c|}
\hline \multirow{2}{*}{ Variables } & \multicolumn{4}{|c|}{ Component } \\
\hline & 1 & 2 & 3 & 4 \\
\hline Family owned teahouse/homestay & 0.781 & & & \\
\hline Local food and service & 0.762 & & & \\
\hline Historic \& religious places & 0.678 & & & \\
\hline Behavior \& cordiality of local people & 0.593 & & & \\
\hline Jungle safari and sight seeing & & 0.768 & & \\
\hline Relaxing environment & & 0.767 & & \\
\hline Personal safety \& security & & 0.689 & & \\
\hline Experiencing different lifestyle & & 0.547 & & \\
\hline Trekking and mountaineering & & & 0.814 & \\
\hline Culture and festivals & & & 0.808 & \\
\hline Adventure sports & & & 0.664 & \\
\hline Communication facilities & & & & 0.788 \\
\hline Tourist guide service & & & & 0.740 \\
\hline Kaiser-Meyer-Olkin Measure of Sampling Adequacy & & & & \\
\hline Determinant Score & & & & \\
\hline Initial Eigenvalue $(>1)$ & 4.02 & 1.67 & 1.24 & 1.03 \\
\hline$\%$ of variance explained (61.27\%) & 17.48 & 17.37 & 15.83 & 10.60 \\
\hline Cronbach's Alpha (Reliability) & 0.739 & 0.735 & 0.711 & 0.45 \\
\hline Average Variance Extracted (AVE) & 0.50 & 0.50 & 0.59 & 0.58 \\
\hline Composite Reliability (CR) & 0.80 & 0.79 & 0.81 & 0.74 \\
\hline
\end{tabular}


The factor extraction method is based on principal component analysis and varimax orthogonal rotation with Kaiser normalization. Before extraction, there were 13 linear components within the data set. After extraction and orthogonal rotation, there are 4 linear components within the data set for which eigenvalue is greater than 1. All the variables having factor loadings greater than 0.4 are taken, thus, confirming convergent validity of the measurement scales (Ho, 2006 [39]; Hair et al., 1998 [40]).

The result from extraction method shows that $61.27 \%$ common variance shared by 13 variables can be accounted by 4 factors. The first component labeled as "people and heritage" described $17.48 \%$ variance with eigenvalue 4.02 . This component includes four destination satisfaction items such as family owned teahouses/homestay, local food \& service, historic \& religious places, and behavior \& cordiality of local people. The second component marked as "natural environment \& beauty" illuminated $17.37 \%$ variance with eigenvalue 1.67 . This component incorporates four satisfaction items such as jungle safari \& sight seeing, relaxing environment, personal safety, \& security, and experiencing different lifestyle.

The third component named as "adventure" portrayed $15.83 \%$ variance with eigenvalue 1.24. This component comprises three destination satisfaction items such as trekking and mountaineering, culture \& festivals, and adventure sports like water sports, bungee, and paragliding. The fourth component entitled as "tourist information" depicted $10.60 \%$ variance with eigenvalue 1.03 . This component embraces two items such as communication facilities and tourist guide service related to destination satisfaction of budget travellers.

Cronbach's alpha is calculated to examine the internal consistency or reliability of the data set. Cronbach's alpha values for first, second and third components are $0.739,0.735$, and 0.711 respectively, which are more than 0.7 (Fornell \& Larcker, 1981) [41]. The coefficient of reliability for the fourth component "tourist information" is poor $(0.45<0.7)$. The overall Cronbach's alpha is 0.76 including all 13 items. The value of average variance extracted (AVE) greater than or equal to 0.5 ratifies value for component $1,2,3$, and 4 are $0.80,0.79,0.81$, and 0.74 respectively, which measures the internal consistency in scale items.

\subsection{Binary Probit Model}

Table 3 demonstrates the results estimated from binary probit model using maximum likelihood method. The dependent variable revisit intention (RI), is a discrete variable that represents the mutually exclusive categories of budget travellers' intention to revisit the destination or not.

The probit model is used to model a relationship between a dependent variable RI and all 13 independent variables. The independent variables are assumed to affect the choice of repeat tourism, and signify a priori beliefs about the associative features important in the choice process. The model has been estimated by the maximum likelihood method. The estimated coefficients and standard errors disclose the factors that influence budget travellers' intention to revisit. 
Table 3. Estimates of the binary probit model.

\begin{tabular}{|c|c|c|c|c|}
\hline Variable & Coefficient & Std. error. & z-statistics & $\begin{array}{c}\text { Marginal } \\
\text { effects }\end{array}$ \\
\hline Constant & $-32.02^{* * *}$ & 7.72 & -4.15 & - \\
\hline Tourist guide service & $0.54^{*}$ & 0.28 & 1.94 & 0.035 \\
\hline Communication facilities & -0.011 & 0.26 & -0.04 & -0.0007 \\
\hline Adventure sports & $2.14^{\star * *}$ & 0.68 & 3.15 & 0.139 \\
\hline Culture and festivals & -0.33 & 0.45 & -0.72 & -0.021 \\
\hline Trekking and mountaineering & $1.13^{*}$ & 0.61 & 1.83 & 0.074 \\
\hline Personal safety \& security & 0.28 & 0.48 & 0.59 & 0.018 \\
\hline Relaxing environment & -0.26 & 0.51 & -0.51 & -0.017 \\
\hline Jungle safari and sight seeing & 0.93 & 0.58 & 1.61 & 0.061 \\
\hline Experiencing different lifestyle & $1.64^{\star * *}$ & 0.61 & 2.68 & 0.11 \\
\hline Local food and service & 0.21 & 0.37 & 0.56 & 0.014 \\
\hline Family owned teahouse/homestay & 0.47 & 0.39 & 1.19 & 0.03 \\
\hline Behavior \& cordiality of local people & $1.09^{\star *}$ & 0.49 & 2.21 & 0.072 \\
\hline Historic \& religious places & $0.94^{* *}$ & 0.43 & 2.17 & 0.062 \\
\hline Log-Likelihood & \multicolumn{2}{|c|}{-24.295} & Akaike IC & 0.383 \\
\hline McFadden Pseudo- $\mathrm{R}^{2}$ & \multicolumn{2}{|c|}{0.707} & Bayesian IC & -936.89 \\
\hline $\operatorname{LR~Chi~}^{2}(\mathrm{df}=13)$ & \multicolumn{2}{|c|}{116.98} & & \\
\hline Significance level & \multicolumn{2}{|c|}{0.0001} & & \\
\hline Predicted percentage correction & \multicolumn{2}{|c|}{93.5} & & \\
\hline
\end{tabular}

Note: $\left.{ }^{*}\right),\left({ }^{* *}\right),\left({ }^{* * *}\right)$ denote significance at the $10 \%, 5 \%$, and $1 \%$ levels, respectively.

A statistically significant coefficient at $5 \%$ level of probability indicates that the likelihood of revisit intention of the traveller will increase if the value of the independent variable increases (Liao, 1994 [34]; Borooah, 2002 [42]). The likelihood ratio chi-square of 116.98 with a p-value of 0.0001 indicates that the model as a whole is statistically significant, that is, it fits significantly better than the model with no predictors. The probit regression coefficients provide the variation in the z-score or probit index for a unit change in the independent variable (Long, 1997) [43].

McFadden's Pseudo- $\mathrm{R}^{2}$ was calculated as 0.71 , which demonstrates that the explanatory variables included in the probit model illuminate significant proportion of the variations to revisit the destination or not. $71 \%$ McFadden's Pseudo- $\mathrm{R}^{2}$ also indicates that variables assigned in the probit model explain high level of the probabilities of revisit intention of the budget traveller. The correct 
prediction rate attained from the binary probit model is $93.5 \%$, which indicates that this model predicts $93.5 \%$ of the cases correctly.

The predictor variables tourist guide service, adventure sports, trekking and mountaineering, experiencing different lifestyle, behavior \& cordiality of local people, and historic \& religious places have statistically significant effect on the revisit intention of the budget traveller at $10 \%, 5 \%$ and $1 \%$ level of significance. These variables were also found to be important determinants of revisit intention by previous studies (Kozak, 2001 [17]; Seetanah et al., 2020 [19]; Bam \& Kunwar, 2020 [26]; Mok et al., 1995 [44]). The variables considered in this study were relevant to the budget travellers visiting Gandaki province but may not be appropriate to the mainstream tourists visiting other destination. There are very few studies that considered tourists' satisfaction and their repeat visit to Nepal. The finding of this study is consistent with the studies in which predictors hospitality service, qualities of activities around the destination, adventure, behavior of people, and cost of a stay significantly influenced the tourist overall satisfaction and satisfaction influenced revisit intention (Bigne et al., 2009 [15]; Um et al., 2006 [16]; Bam \& Kunwar, 2020 [26]).

Table 3 also demonstrates the average marginal effects. The marginal effect for the variable satisfaction with tourist guide service is 0.035 ; it means the probability of revisit intention of travellers will increase by $3.5 \%$. According to marginal effect, for a predictor satisfaction with adventure sports, the probability of revisiting the destination is increased by $14 \%$. The marginal effect of the variable satisfaction with trekking and mountaineering is 0.074 ; it indicates that the probability of revisit intention will increase by $7.4 \%$. The marginal effect of variable satisfaction with experiencing different lifestyle will increase intention of revisit by $11 \%$. The marginal effect of satisfaction with behavior \& cordiality of local people will increase to revisit intention by $7.2 \%$. The marginal effect value (0.062) indicates that the budget travellers' satisfaction with historic \& religious places is $6.2 \%$ more likely to have to revisit intention.

To sum up, the present study reveals the male participants were more than the female to visit Gandaki province of Nepal. The participants of this study were assumed to be budget travellers. The mean age of participants was 35.7 years. The majority (80\%) of the tourists were from the age group 16 to 45 years. More than half (58.5\%) of the participants were from Asian countries. $30.5 \%$ of the tourist visited for the purpose of adventure including trekking and mountaineering. The average length of stay of participants was 12.72 days. The tourists were considered to be budget travellers as $92 \%$ of them spent less than $\$ 40$ per person per day during their visit. The socio-demographic findings are consistent with the Nepal tourism statistics report published in 2020 (MoCTCA, 2020) [4].

Using factor analysis, four components were extracted as a major constructs associated to the satisfaction of budget travellers. They were people and heritage, natural environment and beauty, adventure, and tourist information. Similar constructs were observed in the previous literature (Bigne et al., 2009 [15]; Um 
et al., 2006 [16]; Bam \& Kunwar, 2020 [26]). The probit model predicts $93.5 \%$ of the cases correctly. The outcome of probit model analysis shows that satisfaction with destination characteristics such as historic and religious places, experiencing different lifestyle, trekking \& mountaineering, adventure sports, and tourist guide service are realized to significantly influence the probability of revisit intention of budget travellers to Nepal.

\section{Conclusions}

This study discussed on the satisfaction of budget travellers with various destination attributes that influence their intention to revisit to Nepal. The findings of this study disclosed that various features of destination satisfaction included in the survey questionnaire were extracted by factor analysis into four components such as people and heritage, natural environment \& beauty, adventure, and tourist information. The influences of all 13 factors on revisit intention of budget travellers were examined using binary probit model.

The result of probit model revealed that the predictors of destination satisfaction with tourist guide service, adventure sports, trekking \& mountaineering, experiencing different lifestyle, behavior \& cordiality of local people, and historic $\&$ religious places have statistically significant effect on the revisit intention of the budget traveller. The present study makes use of cross-sectional data with non-probability sampling method, so it cannot be generalized for the large population. However, the findings of the study will be beneficial to the stakeholders of tourism industry to make plan and policy.

\section{Conflicts of Interest}

The author declares no conflicts of interest regarding the publication of this paper.

\section{References}

[1] Terry, V.L. (2006) Tourism Management: New Research. Nova Science Publishers, New York.

[2] Kevin, H. and Irena, A. (2007) Backpacker Tourism: Concepts and Profiles (Tourism and Cultural Change). Channel View Publications, Clevedon.

[3] MoCTCA (2019) Nepal Tourism Statistics 2018. Ministry of Culture, Tourism \& Civil Aviation, Government of Nepal.

[4] MoCTCA (2020) Nepal Tourism Statistics 2019. Ministry of Culture, Tourism \& Civil Aviation, Government of Nepal.

[5] Richards, G. and Wilson, J. (2004) The Global Nomad: Backpacker Travel in Theory and Practice. Channel View Publications, Clevedon. https://doi.org/10.21832/9781873150788

[6] Maoz, S. (2007) Backpackers' Motivations the Role of Culture and Nationality. Annals of Tourism Research, 34, 122-140. https://doi.org/10.1016/j.annals.2006.07.008

[7] NTB (2020) Tourist Arrival Summary 2020. Nepal Tourism Board: Government of Nepal.

[8] Lehto, X.Y., O'Leary, J.T. and Morrison, A.M. (2004) The Effects of Prior Expe- 
rience on Vacation Behavior. Annals of Tourism Research, 31, 801-818. https://doi.org/10.1016/j.annals.2004.02.006

[9] Julaimi, A.R. and Salim, A.T. (2016) International Tourists Revisit Intention: A Case of the United Arab Emirates. Journal of Tourism, Hospitality \& Culinary Arts, 8, 35-42.

[10] Bake, D.A. and Crompton, J.L. (2000) Quality, Satisfaction and Behavioral Intentions. Annals of Tourism Research, 27, 785-804. https://doi.org/10.1016/S0160-7383(99)00108-5

[11] Khan, M.J., Chelliah, S. and Ahmed, S. (2017) Factors Influencing Destination Image and Visit Intention among Young Women Travellers: Role of Travel Motivation, Perceived Risks, and Travel Constrains. Asia Pacific Journal of Tourism Research, 22, 1139-1155. https://doi.org/10.1080/10941665.2017.1374985

[12] Sonmez, S.F. and Graefe, A.R. (1998) Determining Future Travel Behavior from Past Travel Experience and Perception of Risk and Safety. Journal of Travel Research, 37, 171-177. https://doi.org/10.1177/004728759803700209

[13] Pritchard, M. and Howard, D.R. (1997) The Loyal Traveler: Examining a Typology of Service Patronage. Journal of Travel Research, 35, 2-10. https://doi.org/10.1177/004728759703500401

[14] Juaneda, C. (1996) Estimating the Probability of Return Visits Using a Survey of Tourist Expenditure in the Balearic Islands. Tourism Economics, 2, 339-352. https://doi.org/10.1177/135481669600200404

[15] Bigne, J.E., Sanchez, I. and Andreu, L. (2009) The Role of Variety Seeking in Short and Long Run Revisit Intentions in Holiday Destinations. International Journal of Culture, Tourism and Hospitality Research, 3, 103-115. https://doi.org/10.1108/17506180910962113

[16] Um, S., Chon, K. and Ro, Y. (2006) Antecedents of Revisit Intention. Annals of Tourism Research, 33, 1141-1158. https://doi.org/10.1016/j.annals.2006.06.003

[17] Kozak, M. (2001) Repeaters' Behavior at Two Distinct Destinations. Annals of Tourism Research, 28, 784-807. https://doi.org/10.1016/S0160-7383(00)00078-5

[18] Loi, L.T.I., So, A.S.I., Lo, I.S. and Fong, L.H.N. (2017) Does the Quality of Tourist Shuttles Influence Revisit Intention through Destination Image and Satisfaction? The Case of Macao. Journal of Hospitality \& Tourism Management, 32, 115-123. https://doi.org/10.1016/j.jhtm.2017.06.002

[19] Seetanah, B., Teeroovengadum, V. and Nunkoo, R. (2020) Destination Satisfaction and Revisit Intention of Tourists: Does the Quality of Airport Services Matter? Journal of Hospitality \& Tourism Research, 44, 134-148. https://doi.org/10.1177/1096348018798446

[20] Pradhanang, B.S. (2000) Tourists' Consumption Pattern and Its Economic Impact in Nepal. Adroit Publisher, Delhi.

[21] Shrestha, P.H. (2000) Tourism in Nepal: Marketing Challenges. Nirala, Delhi.

[22] Hampton, M. (2010) Backpacker Tourism Can Be Beneficial for Poor Countries. The Guardian. https://www.theguardian.com/commentisfree/2010/sep/24/backpack

[23] Scheyvens, R. and Russell, M. (2012) Tourism and Poverty Alleviation in Fiji: Comparing the Impacts of Small and Large Scale Tourism Enterprises. Journal of Sustainable Tourism, 20, 417-436. https://doi.org/10.1080/09669582.2011.629049

[24] Pearce, D.G. (2008) Beyond Tiers: A Network Approach to Tourism Distribution. Tourism Analysis, 13, 517-530. https://doi.org/10.3727/108354208788160496

[25] MoITFE (2019) Major Tourist Destinations (Gandaki Province), Provincial Gov- 
ernment: Ministry of Industry, Tourism, Forest and Environment, Nepal.

[26] Bam, N. and Kunwar, A. (2020) Tourist Satisfaction: Relationship Analysis among Its Antecedents and Revisit Intention. Advances in Hospitality and Tourism Research, 8, 30-47. https://doi.org/10.30519/ahtr.519994

[27] Kimberly, K.L. (2005) Encyclopedia of Social Measurement, Vol. 2. Elsevier, Amsterdam.

[28] Lavrakas, P.J. (2008) Encyclopedia of Survey Research Methods, Vol. 2. Sage Publications, London. https://doi.org/10.4135/9781412963947

[29] Shrestha, N. (2021) Factor Analysis as a Tool for Survey Analysis. American Journal of Applied Mathematics and Statistics, 9, 4-11. https://doi.org/10.12691/ajams-9-1-2

[30] Uzunoz, M. and Akcay, Y. (2012) A Case Study of Probit Model Analysis of Factors Affecting Consumption of Packed and Unpacked Milk in Turkey. Economics Research International, 2012, 324-331. https://doi.org/10.1155/2012/732583

[31] Cattel, R.B. (1979) Factor Analysis. Greenwood Press, Westport.

[32] Kaiser, H.F. (1958) The Varimax Criterion for Analytic Rotation in Factor Analysis. Psychometrika, 23, 187-200. https://doi.org/10.1007/BF02289233

[33] Alabi, O.O., Lawal, A.F., Coker, A.A. and Awoyinka, Y.A. (2014) Probit Model Analysis of Smallholder's Farmer's Decision to Use Agrochemical Inputs in Gwagwalada and Kuje Area Councils of Federal Capital Territory, Abuja, Nigeria. International Journal of Food and Agricultural Economics, 2, 1-9.

[34] Liao, F.T. (1994) Interpreting Probability Models: Logit, Probit and Other Generalized Linear Models, 101, Quantitative Applications in the Social Sciences. Sage Publications, London.

[35] Albert, J.H. and Chib, S. (1993) Bayesian Analysis of Binary and Polychotomous Response Data. Journal of the American Statistical Association, 88, 669-679. https://doi.org/10.1080/01621459.1993.10476321

[36] Aldrich, J.H. and Nelson, F.D. (1984) Linearity Probability, Logit and Probit Models. Sage Publications, London. https://doi.org/10.4135/9781412984744

[37] Greene, W.H. (1993) Econometric Analysis. 2nd Edition, Macmillan, New York.

[38] Shrestha, N. (2020) Detecting Multicollinearity in Regression Analysis. American Journal of Applied Mathematics and Statistics, 8, 39-42. https://doi.org/10.12691/ajams-8-2-1

[39] Ho, R. (2006) Handbook of Univariate and Multivariate Data Analysis and Interpretation with SPSS. Chapman \& Hall, Boca Raton. https://doi.org/10.1201/9781420011111

[40] Hair, J.F., Anderson, R.E., Tatham, R.L. and Black, W.C. (1998) Multivariate Data Analysis. 5th Edition, Prentice Hall, Upper Saddle River.

[41] Fornell, C. and Larcker, D.F. (1981) Evaluating Structural Equation Models with Unobservable Variables and Measurement Error. Journal of Marketing Research, 18, 39-50. https://doi.org/10.1177/002224378101800104

[42] Borooah, V.K. (2002) Logit and Probit: Ordered and Multinomial Models. Series Quantitative Applications in the Social Science, Vol. 138. Sage Publications, London. https://doi.org/10.4135/9781412984829

[43] Long, J.S. (1997) Regression Models for Categorical and Limited Dependent Variables. Sage Publications, London.

[44] Mok, C., Armstrong, R.W. and Go, F.M. (1995) Taiwanese Travellers' Perception of Leisure Destination Attributes. Australian Journal of Hospitality Management, 2, $17-22$. 